\title{
RETRACTED ARTICLE: The Fleet Deployment Problem with Variable Vessel Sailing Speeds and Port Handling Times
}

\author{
M. A. Dulebenets*, M. M. Golias**, and S. Mishra***
}

Received April 23, 2015/Revised November 10, 2015/Accepted November 29, 2015

The Editors of KSCE Journal of Civil Engineering have decided to retract this article for reasons of duplication. Investigation by the Editors revealed substantial overlap throughout the entire text with this previously-published article:

M. A. Dulebenets, M. M. Golias, and S. Mishra (2015). "The green vessel schedule design problem: consideration of emissions constraints” Energy Systems, DOI 10.1007/s12667-015-0183-3.

The online version of this article contains the full text of the retracted article as electronic supplementary material.

*Research Associate II, Dept. of Civil Engineering and Intermodal Freight Transportation Institute, The University of Memphis, 302A Engineering Admin. Bldg., 3815 Central Ave Memphis, TN 38152, USA (Corresponding Author, E-mail: mdlbnets@memphis.edu)

**Associate Professor, Dept. of Civil Engineering, and Associate Director for Research, Intermodal Freight Transportation Institute, The University of Memphis, 104B Engineering Science Bldg., 3815 Central Ave Memphis, TN 38152, USA (E-mail: mgkolias@memphis.edu)

***Assistant Professor, Dept. of Civil Engineering, The University of Memphis, 112D Engineering Science Bldg., 3815 Central Ave Memphis, TN 38152, USA (E-mail: smishra3@memphis.edu) 